\title{
CONVENTIONAL COMPLETE DENTURE FOR A PATIENT WITH MALUNITED FRACTURE OF MANDIBLE: A CASE REPORT
}

\author{
Dr. Monica Sharma ${ }^{1}$, Dr. Jagmohan Lal ${ }^{2}$, Dr. Ravneet Kaur ${ }^{3}$, Dr.Mandeep Kumar ${ }^{4}$, Dr.Bhavna Sharma \\ 1. PG Student, Department of Prosthodontics, Bhojia Dental College \& Hospital, Distt. Solan, Himachal Pradesh (India) \\ 2. Prof. \& Head, Department of Prosthodontics, Bhojia Dental College \& Hospital, Distt. Solan, Himachal Pradesh (India) \\ 3. Professor, Department of Prosthodontics, Bhojia Dental College \& Hospital, Distt. Solan, Himachal Pradesh (India) \\ 4. Reader, Department of Prosthodontics, Bhojia Dental College \& Hospital, Distt. Solan, Himachal Pradesh (India) \\ 5. P.G. Student, Department of Prosthodontics, Bhojia Dental College \& Hospital, Distt. Solan, Himachal Pradesh (India) \\ Corresponding Author: \\ ${ }^{1}$ Mobile: 918894626680 Email: drmonica.sharma@yahoo.com
}

Received :

$21^{\text {st }}$ May, 2013

Accepted:

$9^{\text {th }}$ August, 2013

Available online:

$25^{\text {th }}$ August, 2013

\section{ABSTRACT}

A patient with malunited fracture of mandible require preprosthic reconstructive surgery followed by implantassisted overdentures. In this case report, conventional complete dentures were fabricated for the patient as he refused any invasive treatment. The fabrication procedure of the denture was carefully modified according to anatomical and functional situation of the patient to achieve adequate retention and stability. Complete dentures thus fabricated provided comfort and sufficient function to the patient.

Keywords: Oral preposthetic surgery, Denture, Denture stability.

\section{INTRODUCTION}

The rehabilitation of a patient following trauma presents a unique prosthetic challenge. The most common prosthetic treatment problem with such patients is, getting adequate retention, stability and support. All basic principles of complete denture construction must be considered, and the manner in which these principles are applied and interpreted must be modified because of the unusual anatomic and functional situation. ${ }^{1}$

Bilateral fractures of the edentulous mandible frequently occur from a combination of direct and indirect impact requiring surgical management. ${ }^{2-7}$ The normal healing process of fracture is divided into 4 temporal phases: inflammatory, chondrogenic, osteogenic, and remodeling, each characterized by specific tissue differentiation events. ${ }^{8}$ Normal healing is "bony union," in which the fractured bone end is united by new bone tissue, with anatomic reduction and fixation resulting in restoration of function and prevention of deformities. ${ }^{9}$ Although most fractures heal, some fail to heal and become abnormal unions such as bony malunion, delayed union, nonunion, and pseudoarthrosis. ${ }^{9-12}$

Virtually, malunion is "bony union" and the fractured bone ends are united by normal bony image in radiograph. However, the normal anatomic structure isn't restored because of the unsatisfactory reduction. ${ }^{9}$ For these patients, if necessary, the malunion should be treated by refracture and repositioning. ${ }^{13,14}$

Without preprosthetic reconstructive surgery, denture fabrication in such patients becomes extremely difficult. After reconstructive surgery, implantassisted overdentures may improve denture retention and stability, but some patients cannot afford this treatment. In such patients, conventional complete dentures are constructed with certain modifications to enhance retention and stability. ${ }^{1}$ Therefore, this article describes the fabrication of conventional complete dentures for a patient with malunited fracture of the mandible. 


\section{CASE REPORT}

Patient examination, diagnosis and treatment planning

A 65yr old male patient came to the Department of Prosthodontics, at Bhojia Dental college and Hospital, with the chief complaint of difficulty in chewing and mastication after having lost all his teeth. A detailed case history revealed, history of assault by a family member 3yrs back resulting in vertical fracture of mandible at right body and left parasymphysis region. The patient was operated 2 months after the assault. On the left side the patient was operated with intra-oral rigid internal fixation (IORIF) with $2.5 \mathrm{~mm}, 4$ hole titanium plating. The right body fracture was operated subsequently in second surgery with $3 \mathrm{~mm}, 5$ hole titanium reconstruction plate. However, the reduction was unsatisfactory and the patient's face showed assymetery after the surgery.

Dental history revealed that the patient was edentulous for past 4 yrs with no history of previous use of dentures. No radiographic records of the previous treatment were available with the patient.

Extraoral examination (Figure 1) revealed assymetery and step-deformity in the lower mandibular border of right side. Residual scar could be seen in the lower back cheek region of the right side.

Intraoral examination (Figure 2) showed that the shape and form of mandibular ridge was assymetrical because of malunion, resulting in shortening of length of right arch with reduced buccal shelf and retromolar pad area. However, the retromylohyoid space of the right arch was extended probably due to inferior placement of attached muscles after surgery.

Ortho pan-tomogram (Figure 3) revealed presence of titanium plates and step-deformity at the lower border of right side of mandible.

When given the option of surgical reconstruction of the defect, patient refused an additional surgery and requested a noninvasive and economical treatment option. Therefore, it was decided that conventional complete dentures would be fabricated without any further surgical procedure.

\section{FABRICATION OF COMPLETE DENTURE PROSTHESIS}

Stainless steel stock edentulous trays and impression compound (Y-Dents impression compound; MDM Corporation, New Delhi, India) were used to record the preliminary impressions. Special consideration was given to the right back region of the mandible which required molding of the tray (Figure 4) according to the shape of the ridge on buccal and distal border. More extension was achieved in the right alveololingual sulcus because the tongue movement was little restricted.

Self-cure acrylic (DPI Cold Cure; Dental products of India, Mumbai, India) custom trays were fabricated with full spacer technique, for both maxilla and mandible. Border molding (Figure 5) was done with low-fusing impression compound (DPI Pinnacle; Dental products of India, Mumbai, India) and secondary impression (Figure 6) made with ZOE impression paste (DPI Impression paste, Dental products of India, Mumbai, India).

Due to malalignment of the lower jaw with respect to upper, horizontal jaw relation was recorded in "habitual position" "15 and not in centric relation. Zerodegree teeth (Premadent; Super dental products, Delhi, India) were used. On the right side first premolar and second molar were eliminated in the arrangemen (Figure 7).

After try-in dentures (Figures 8,9) were processed in heat-cure acrylic resin (DPI Heat Cure; Dental products of India, Mumbai,India) by conventional technique.

\section{DENTURE INSERTION AND POST- INSERTION CARE}

Occlusion of the denture was evaluated and adjusted intraorally (Figure 10). Post-insertion instructions were given. Patient was recalled after $24 \mathrm{hrs}$ for necessary modifications. The extensions of the alveololingual sulcus in the posterior region were left as such. After $24 \mathrm{hrs}$ of observation patient did not complain of any soreness or difficulty in swallowing in this region. To examine his adaptability to the dentures and level of satisfaction, patient was followed further at regular interval of 2 months, for initial 1 year. 


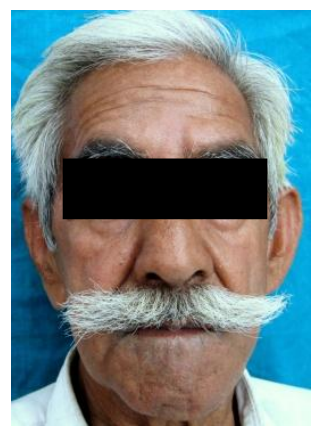

Figure 1: Extraoral view of the patient showing facial assymetery
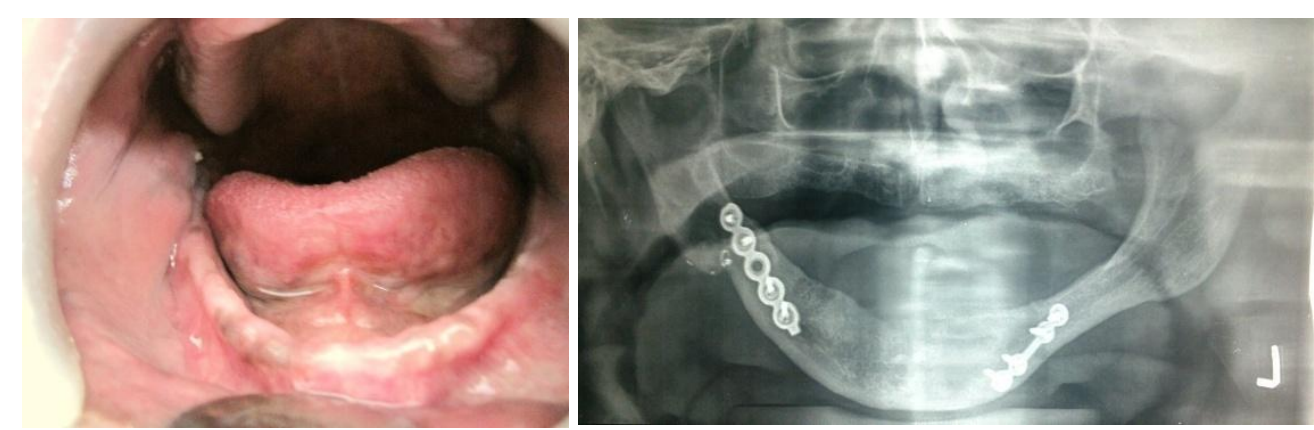

Figure 2: Intraoral view of the patient Figure 3: Ortho pan-tomogram (OPG) showing titanium showing obliterated buccal shelf and plating at right body and left parasymphysis region of the retromolar pad area mandible

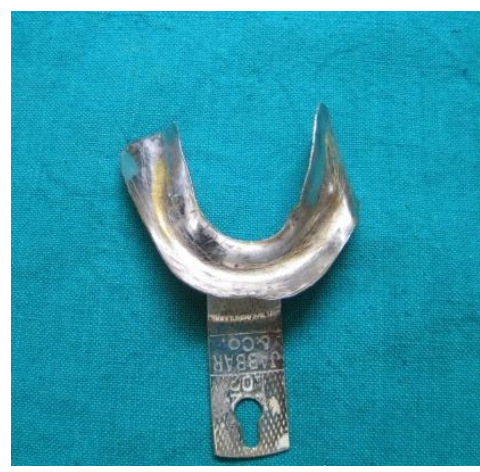

Figure 4: Molded stainless steel stock tray

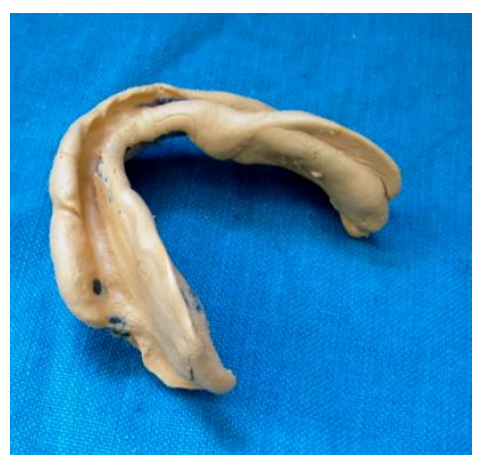

Figure 7: Mandibular secondary impression

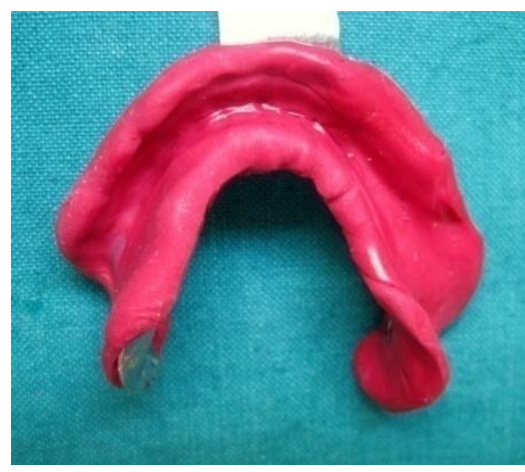

Figure 5: Preliminary mandibular impression

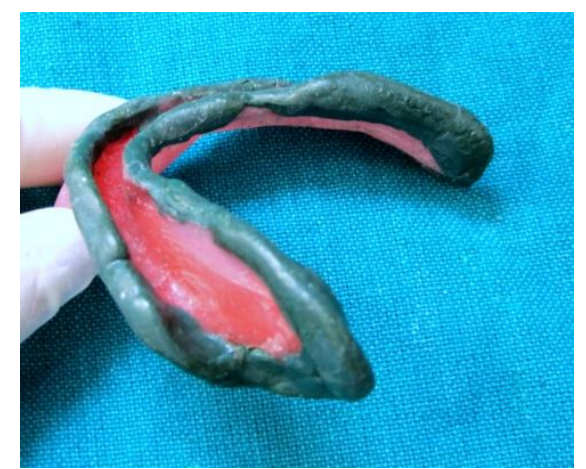

Figure 6: Mandibular border molding in custom tray

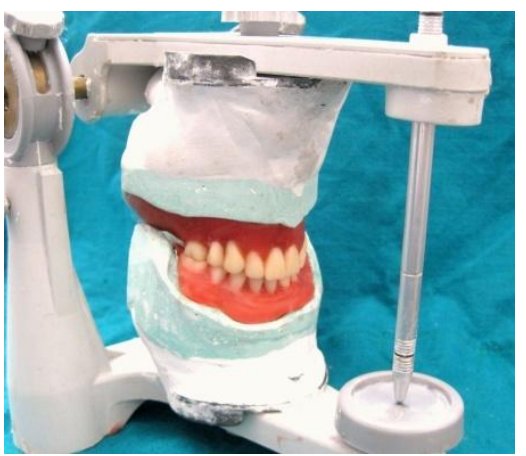

Figure 8: Teeth Arrangement

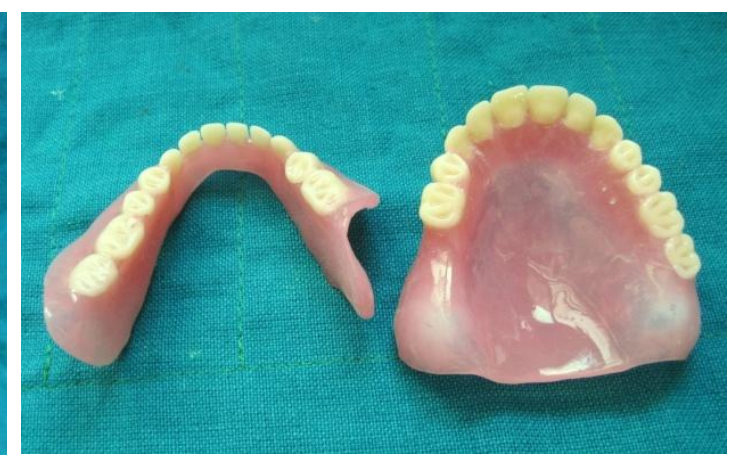

Figure 9: Polished and occlusal surface of the denture fabricated

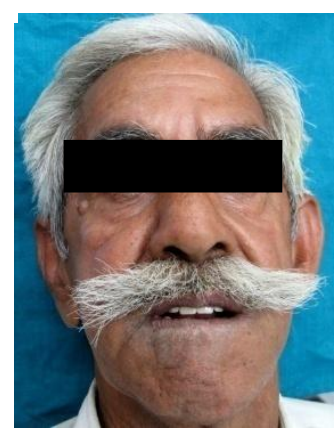

Figure 11: Extra-oral view of the patient with prosthesis
Figure 10: Alveololingual extension of

mandibular denture

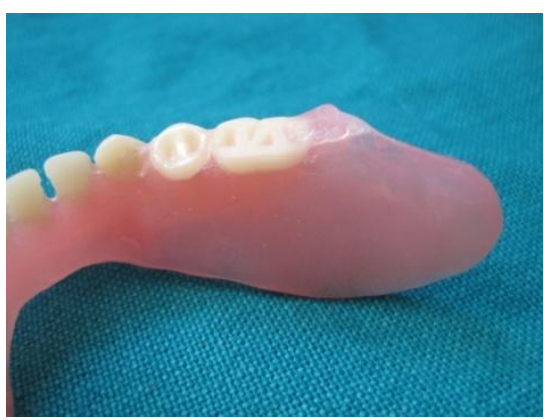




\section{DISCUSSION}

Trauma followed by malunion of the fracture affected the mandibular ridge form and shape in the patient. The loss of right buccal shelf and retromolar pad at the fracture site, resulted in assymetery of the arch. To achieve denture stability proper border extensions, polished denture surface contours and harmonious occlusion were developed.

During preliminary impression stock tray was modified according to ridge form and reccord the maximum area coverage. The extension into the alveololingual sulcus provided guidance for placement, stability and retention of lower denture.

There was difficulty in recording centric relation of the patient. This may be due to trauma to the tissues which was followed by surgical intervention. So the patient had acquired a new "habitual position" 15 and the horizontal jaw relation were recorded in this position.

Use of zero degree teeth provided stability to the dentures by allowing lateral freedom of mandibular movements. The assymetrical arrangement of teeth was accepted by the patient because of assymetery of the arch.

Periodic patient recall was important to evaluate patient adaptability and satisfaction to the dentures.

\section{CONLUSION}

Though the denture bearing tissues had modified form and shape, the polished surface, occlusal surface and tissue surface of the prosthesis were carefully modified to give favorable denture stability. Application of conventional prosthodontic principles along with patient cooperation can achieve long term success of prosthesis and predictable patient satisfaction in such compromised situations.

\section{REFERENCES}

1. Schaaf NG. Oral reconstruction for edentulous patients after partial mandibulectomies. J Prosthet Dent. 1976 Sep;36(3):292-7.

2. Eyrich GK, Grätz KW, Sailer HF. Surgical treatment of fractures of the edentulous mandible. J Oral Maxillofac Surg. 1997 Oct;55(10):1081-7.

3. Levine PA, Goode RL. Treatment of fractures of the edentulous mandible. Arch Otolaryngol. 1982 Mar;108(3):167-73.

4. Thaller SR. Fractures of the edentulous mandible: a retrospective review. J Craniofac Surg. 1993 Apr;4(2):91-4.

5. Kunz C, Hammer B, Prein J. Fractures of the edentulous atrophic mandible. Fracture management and complications. Mund Kiefer Gesichtschir. 2001 Jul;5(4):227-32.

6. Ellis E 3rd, Price C. Treatment protocol for fractures of the atrophic mandible. J Oral Maxillofac Surg. 2008 Mar;66(3):421-35.

7. Knotts C, Workman M, Sawan K, El Amm C. A novel technique for attaining maxillomandibular fixation in the edentulous mandible fracture. Craniomaxillofac Trauma Reconstr. 2012 Mar;5(1):7-10.

8. McKibbin B: The biology of fracture healing in long bones.J Bone Joint Surg Br 60B:150, 1978.

9. Li Z, Zhang W, Li ZB, Li JR. Abnormal union of mandibular fractures: a review of 84 cases. J Oral Maxillofac Surg. 2006 Aug;64(8):1225-31.

10. Furr AM, Schweinfurth JM, May WL. Factors associated with long-term complications after repair of mandibular fractures. Laryngoscope 2006 Mar;116(3):427-30.

11. De Souza M, Oeltjen JC, Panthaki ZJ, Thaller SR. Post traumatic mandibular deformities. J Craniofac Surg. 2007 Jul;18(4):912-6.

12. Zweig BE. Complications of mandibular fractures. Atlas Oral Maxillofac Surg Clin North Am. 2009 Mar;17(1):93101.

13. Thaller SR, Reavie D: Refracture reposition of mandibular malunion. Ann Plast Surg 25:188, 1990.

14. Vega LG. Reoperative mandibular trauma: management of posttraumatic mandibular deformities. Oral Maxillofac Surg Clin North Am. 2011 Feb;23(1):47-61.

15. Levy PH. A form and function concept of occlusion and the maxillomandibular relationship. J Prosthet Dent. 1975 Feb;33(2):149-57.

Source of Support: Nil, Confilict of Interst: None Declared 